\title{
La pelea del Siglo XX; prensa, masculinidad y nacionalidad $^{1}$
}

\author{
The Fight of the 20th Century; press, masculinity and \\ nationality
}

\author{
Antonella Bertolotto \\ Orcid: https://orcid.org/0000-0002-1356-7589 \\ Departamento de Educación Física, Universidad Nacional de La Plata, La Plata, \\ Argentina, antob1996@hotmail.com
}

Received on 20/05/2020 - Approved on 30/05/2020

\section{Resumen}

Se analizará la famosa pelea de boxeo entre Luis Ángel Firpo y Jack Dempsey, realizada el 14 de septiembre de 1923 en el Polo Grounds de Nueva York, Estados Unidos, a partir de la historia sociocultural de la prensa escrita argentina. Se utiliza un análisis cuali-cuantitativo de fuentes primarias de los periódicos de $\mathrm{La}$ Prensa, La Nación, La Razón y Crítica para visibilizar y poner en diálogo los discursos y sentidos, puestos en circulación sobre la masculinidad y la nacionalidad. La hipótesis afirma que gran parte de la prensa escrita, a partir de uno de los eventos deportivos más importantes de la década del '20, produjo y legitimó ciertos sentidos sobre la masculinidad y la nacionalidad argentina, en contraposición a los sentidos estadounidenses.

Palabras clave: Prensa. Masculinidad. Nacionalidad. Boxeo.

\begin{abstract}
The famous boxing match between Luis Ángel Firpo and Hack Dempsey, which took place in September 14th, 1923 at the Polo Grounds in New York, United States of America, will be analyzed following the sociocultural history of the Argentinian written press. The starting point is a quantitative and qualitative analysis of primary sources from the newspapers La Prensa, La Nación, La Razón y Crítica, in order to highlight and set up a dialogue between the discourses and concepts that were distributed and produced about the masculinity and the nationality. The hypothesis affirms that great part of the written press, using one of the most important sport events of the 20's, produced and legitimized some parts of Argentinian masculinity and nationality, over the American ones.
\end{abstract}

Keywords: Press. Masculinity. Nationality. Boxing. 


\section{Introducción}

Se desarrolla un análisis de la famosa pelea de boxeo entre Luis Ángel Firpo "El Toro salvaje de las Pampas" (1894-1960) y Jack Dempsey "El asesino de Manassas" (1895-1983), realizada el 14 de septiembre de 1923 en el Polo Grounds de Nueva York, Estados Unidos, a partir de la historia social y cultural de la prensa escrita argentina. Partimos de entender a la prensa escrita como un actor social, político, pedagógico y, también, como un espacio de producción cultural y fuente de información histórica (Borrat, 1989; Kircher, 2005; De Diego, 2006; Bontempo, 2012; Qués, 2013; Delgado y Rogers, 2016; Delgado, Mailhe y Rogers, 2014) ${ }^{2}$ que puso en circulación, distribución, transmisión, producción y apropiación en un espacio y tiempo determinados discursos, tópicos y sentidos.

Se utiliza un enfoque cuali-cuantitativo o mixto. Cuantitativo particularmente para el análisis de las publicidades presentes y los principales temas de interés en los periódicos. Cualitativo al momento de considerar las diferentes formas de entender el cuerpo, sexo, género y deporte. La técnica principal a emplear es el análisis de documentos, para ello se revisaran distintos tipos de fuentes primarias. En este caso se analizarán los discursos, tópicos y sentidos acerca de la masculinidad y la nacionalidad argentina, fuertemente relacionados con ser criollo y representante de la raza latina, que fueron contrapuestos, en algún sentido, a los discursos, tópicos y sentidos sobre la masculinidad y la nacionalidad estadounidense, articulada y relacionada con ser yanqueé y representante de la raza sajona.

Para poder realizar dicho análisis se tuvieron en cuenta las fuentes primarias de los periódicos de La Prensa, La Nación, La Razón y Crítica, durante los meses de agosto, septiembre y octubre de 1923. Este recorte y elección, en las fuentes primarias, se debe a la gran importancia que tuvieron estos medios de comunicación en los primeros años de la década del '20. La Prensa (fundado en 1869) y La Nación (fundado en 1870) eran los periódicos de mayor tirada y, por lo tanto, los más importantes de la época, siendo así los periódicos hegemónicos en el espacio de la mañana. La Razón (fundado en 1905) era el tercer periódico en Argentina y el periódico vespertino más importante (Saítta, 1998) y, por último, Crítica (fundado en 1913) que estaba en pleno cambio, desarrollo y expansión para disputar el campo hegemónico del mercado editorial, que estaban en manos de La Prensa y La Nación, y más precisamente, pretendía conquistar el espacio de la tarde, el cual estaba en manos de La Razón (Saítta, 1998 y Bontempo, 2012).

Parte de la prensa escrita argentina, a partir de la pelea entre Luis Ángel Firpo y Jack Dempsey, se ocupó de producir y poner en circulación ciertos discursos, sentidos y tópicos, caracterizando, categorizando y estereotipando lo propio; ser criollo, argentino y latino, contraponiéndolo a las características, categorías y estereotipos del otro(s); ser yanqueé, estadounidense y sajón. De esta manera, dentro del proceso de alteridad, que se construye y reproduce de una forma, por decirlo de alguna manera, "negativa", se produce, legitima y (re) afirma la mismidad a partir del otro, un otro incompleto, inacabado, malo e inferior, en la cual ese otro existe, no por fuera o ajena a la mismidad, sino por dentro de esta (Duschatzky y Skliar, 2000). En palabras de Levinas (2000, p.47), ese "Yo" representa "la identificación por excelencia, el origen del fenómeno mismo de la identidad". Por lo tanto, los discursos, sentidos y tópicos, producidos y puestos en circulación por parte de la prensa escrita argentina fueron los que le dieron forma, 
legitimidad y sentido a las representaciones como colectivo social, y por lo tanto, a la mismidad. Delimitando, a su vez, los espacios de lo propio y de lo ajeno (Guerrero Arias, 2002 y Skliar, 2002), bajo una lógica binaria y viendo al "otro como fuente de todo mal" (Duschatzky y Skliar, 2000, p.2), característico de la modernidad como forma de control y regulación social.

Siendo uno de los eventos deportivos más importantes de la década del '20, caracterizada por medios nacionales e internacionales como la "pelea del siglo", se indagará como excusa para entender las lógicas nacionales, identitarias, morales y de género. Estos discursos, tópicos y sentidos puestos en circulación, distribución y producción por gran parte de la prensa general escrita argentina, toman mayor sentido en el contexto de la década del '20. La cual se caracteriza por cambios sociales, económicos, culturales, políticos, jurídicos y sexuales (Sarlo, 1988; Barrancos, Guy y Valobra, 2014), en conjunto con el gran desarrollo y profesionalización de los medios de comunicación (Sarlo, 1988; Saítta, 1998; Bontempo, 2012 y Rocchi, 2016).

\section{Deporte y Boxeo en el siglo XX en Argentina}

Buenos Aires había tenido un crecimiento muy importante en las dos primeras décadas del siglo XX. Era considerada una cuidad cosmopolitan, desde el punto de vista de su población, gracias a la fuerte llegada de inmigrantes, la gran mayoría de ellos, europeos. La llegada de los inmigrantes generó grandes diferencias raciales, ideológicas, simbólicas, subjetivas, morales, sexuales y de lenguajes, quebrantando la imagen y el sentido homogéneo de la ciudad (Sarlo, 1988; Barrancos, Guy y Valobra, 2014). Debido a esto, se comenzaron a llevar a cabo y reforzaron, los que ya estaban, distintos procesos, tanto implícita como explícitamente, de homogeneización de la cultura, generando discursos, sentidos, imágenes y subjetividades, produciendo las representaciones como colectivo social y la conformación de un estado-nación lo más homogéneo posible. Dentro de este contexto el mercado editorial local estaba en pleno desarrollo y expansión, ampliando y disputando cada vez más espacios para la divulgación de determinados discursos y sentidos, en función de producir cierta opinión pública en la población.

Por lo tanto en las primeras décadas del siglo $\mathrm{XX}$, caracterizada por sus grandes cambios, con el comienzo de la modernidad, la división del trabajo, el crecimiento del público con mayores posibilidades de consumo y con mayor tiempo libre, la construcción de los estados-nación, el gran crecimiento del mercado editorial como medio de comunicación masivo y formador de opinión en el público, acompañado del auge y conformación de espectáculos en Argentina, se produjo como lo denominan Elías y Dunning (1992, p.34), una "deportivización" de los pasatiempos de la sociedad.

En este contexto los deportes eran vistos, más que nada, como formadores de cuerpos normativos para la sociedad, fuertemente atravesados por discursos médicos, morales e higienitas, en función de producir un mejoramiento de la raza. Esto se debía, en parte, a que estaba en pleno auge la "difusión del discurso eugenésico, el porvenir de la raza y preocupaciones por el stock biológico de la nación argentina" (Scharagrodsky, 2019, p.215). Por lo tanto, en este contexto, los deportes también tenían una fuerte implicancia en la formación y (re) producción de identidad e ídolos nacionales, permitiendo así un lugar propicio para el 
despliegue de las narrativas heroicas e identitarias de la época (Archetti, 2008). Propiciando un escenario público, un espacio de lo propio y de lo ajeno, para la construcción de la otredad y de la mismidad, que en conjunto con los medios de comunicación de la época, lograban maximizar el poder simbólico de las prácticas deportivas, poniendo en circulación determinados discursos, sentidos y tópicos, y no otros. En este caso, los discursos y sentidos producidos y puestos en circulación, fueron acerca de la masculinidad y la nacionalidad argentina y la masculinidad y la nacionalidad estadounidense, los cuales toman mayor sentido dentro del contexto social, político, histórico, económico, cultural, racial, moral y sexual de la época.

El origen del boxeo en la Argentina no fue higienista, ni tampoco su principal objetivo, aunque si estaba atravesado por los discursos médicos y morales de la época. El boxeo era, y sigue siendo, considerado como un deporte espectáculo y mercantil, por lo tanto, su origen y principal objetivo no está en el higienismo ni en el cuidado del cuerpo. Su principal objetivo está en generar grandes cantidades de dinero, mientras más dinero genere mejor, produciendo y brindando un gran espectáculo deportivo para sus espectadores. Por otro lado, al igual que la gran mayoría de los deportes de la época, brindaba un gran espacio público para la formación y (re) producción de identidad e ídolos nacionales, desplegando a partir de la figura de los boxeadores, narrativas heroicas e identitarias.

La historia del boxeo en la Argentina comienza a partir de la llegada de boxeadores inmigrantes aficionados al puerto de Buenos Aires. Los cuales peleaban con o sin guantes, tanto en el puerto, como en bares, salones de baile, teatros, en clubes, en terrenos baldíos y en cualquier otro lugar. Estos boxeadores, principalmente eran ingleses, irlandeses, escoses, galeses, estadounidenses, italianos, australianos, entre otros (Palla, 2018). Llegaban a nuestro país, favorecieron la propagación y el desarrollo del pugilismo inglés. Cabe aclarar, que había dos técnicas, métodos y formas de boxeo, las cuales estaban en disputa por imponerse una sobre la otra dentro del mundo del boxeo. Por un lado estaba el "Método Inglés" y por el otro el "Método Norteamericano o Estadounidense". El "Método Inglés" se caracterizaba por un combate elegante, calmo y a distancia, con golpes largos y aparatosos, especialmente con la mano izquierda, y sin mucha efectividad. Realizando movimientos avanzando y retrocediendo por todo el ring, buscando siempre una distancia del oponente, tratando de esquivar los golpes, el knockout (K.O.) y la sangre. Podría decirse que era parecido a un "esgrima de puños" (Auzzani, 1953; Palla, 2018). En cambio el "Método Norteamericano", el utilizado por Jack Dempsey, buscaba generar desplazamientos por el ring rápidos y cortos, buscando siempre una lucha cuerpo a cuerpo o a media distancia, realizando golpes rápidos. Por sobre todas las cosas buscaba que sus golpes y movientes sean efectivos, dejando de lado los movimientos elegantes y sin mucho sentido y eficacia (Auzzani, 1953; Palla, 2018). A medida que fue pasando el tiempo, ambos métodos se fueron perfeccionando y expandiendo por el mundo, pero el que resultó más efectivo, con mejor expansión y aceptación, fue el método proveniente de Estados Unidos, el cual era el método más rápido, efectivo y eficaz.

Durante todo este periodo, donde se produjo la llegada ${ }^{3}$, masificación y popularización del boxeo, como espectáculo público y rentado, hasta su legalización como práctica rentada y de espectáculo en enero de 1924, había zonas donde sí estaba legalizada dicha práctica. En el caso de Buenos Aires, había solamente 4 zonas donde estaba totalmente permitida la práctica y el 
desarrollo del boxeo como espectáculo público y rentado. Estas zonas eran el Mercado Central, Lomas de Zamora, Avellaneda y Barracas, por lo tanto, en dichas zonas y municipios, era donde se concentraba la práctica deportiva, mercantil y de espectáculo. En caso de querer llevar a cabo espectáculos públicos de boxeo en otros municipios, se tenía que pedir permiso a las autoridades del municipio donde se llevaría a cabo dicho espectáculo. En caso de ser negada la autorización, o de no haberla pedido, el espectáculo no podría llevarse a cabo. Sin embargo, muchas veces se realizaban ilícitamente, y contaban con la ayuda de las fuerzas policiales y el cuerpo de inspectores del municipio ${ }^{4}$.

A partir de la gran importancia e interés, tanto nacional como internacional, que cobró la pelea de Luis Ángel Firpo contra Jack Dempsey el 14 de septiembre de 1923, se produjo una gran aceptación en la moral argentina por este deporte espectáculo y mercantil. Considerado por la prensa socialista como bárbaro ${ }^{5}$, bruto, incivilizado, salvaje y repugnante (Guiamet, 2016) y también por buena parte de la sociedad, la cual pensaba que la práctica del boxeo "estaba equiparada, moralmente hablando, a la trata de blancas y mucho peor que el curanderismo o la quiniela" (Zinni, 1976, p. 7). A partir de la pelea del siglo, la historia del boxeo en la Argentina cambió. La Federación Argentina de Box decidió proclamarlo Campeón Argentino Profesional de Peso Pesado, dándole a su vez, la licencia número uno de Boxeador Profesional. Se legalizó la práctica de boxeo como espectáculo público y rentado para toda la Argentina el 3 de enero de 1924, generando una gran expansión y popularización de la práctica a lo largo y ancho del país, convirtiéndose en una posibilidad de ascenso social. Y años después, en conmemoración a esta pelea y a la figura de Luis Ángel Firpo, se celebra el 14 de septiembre el día del boxeador en la Argentina.

\section{Un acontecimiento sin precedentes}

Fue uno de los acontecimientos deportivos más importante de la década del '20, denominada y recordada como "la pelea del siglo" por la gran mayoría de los periódicos de la época, tanto nacional como internacional (Estados unidos, México, Chile, Uruguay, Perú, Europa, etc.). Fue el primer y más grande acontecimiento deportivo transmitido por radio nacional desde el Polo Grounds en Nueva York, Estados Unidos hacia Buenos Aires, Argentina. Recordada por ser la primer pelea de boxeo por un título mundial entre un argentino y un estadounidense, por ser la primera vez que un representante del deporte argentino este en las tapas de revistas y periódicos internacionales, por ser una pelea millonaria, al tener una gran recaudación de dinero ${ }^{6}$ (solo con los tickets vendido superó el millón de dólares) y por la gran expectativa ${ }^{7}$ y exaltación nacional e internacional. Estas emociones no se habían visto antes en la historia, ya que toda América Latina ${ }^{8}$ y el mundo entero estaba expectante de la resolución de la pelea.

Este combate, que "la historia escribirá en letras de oro" ${ }^{9}$, también es recordado y celebrado por el fuerte derechazo de Firpo, el cual logró sacar a Dempsey fuera del ring durante por lo menos 17 segundos, de los cuales el árbitro loca, Johnny Gallagher, solo contó 10 segundos ${ }^{10}$. Dempsey, al ser arrojado fuera del ring, tuvo que ser ayudado por los periodistas, que estaban disfrutando del espectáculo, para volver a entrar al ring y poder seguir peleando. A pesar de haber sido arrojado fuera del ring por el fuerte derechazo de Firpo, y de haber cometido múltiples faltas, la pelea siguió como si nada, y terminó cuando el Campeón 
Mundial de boxeo dejó knockout a Firpo en el segundo round. La pelea solamente duró 3 minutos y 57 segundos, pero fueron los minutos más interminables y apasionantes que hicieron vibrar y temblar con mayor fuerza al pueblo argentino y al estadounidense, a la raza latina y a la sajona, $y$ al mundo entero.

En Buenos Aires la gente se reunió en bares, avenidas principales, clubs y en las sedes de los periódicos, para poder seguir de cerca cada momento de la pelea y estar expectantes, a lo que todos los argentinos suponían y querían que pase, que Luis Ángel Firpo el "Toro salvaje de las Pampas", el ídolo argentino", ganara la pelea y demostrara que en América del Sur también había buen boxeo $^{12}$. Luis Ángel Firpo fue bautizado como "Wild Bull of the Pampas" (El Toro Salvaje de las Pampas) por el periodista norteamericano Damon Runyon. Haciendo referencia a este animal por su brutalidad y potencia, por el enorme tamaño y la forma del cuerpo de Firpo en comparación con el tamaño y la forma del cuerpo de Dempsey, y al espacio de la Pampa como un lugar salvaje y desconocido, el cual había que conocer y domar.

No solo había una pelea de boxeo por el título mundial de los pesos pesados, sino que por debajo, había múltiples y distintas pujas de poder entre los principales actores que conformaban y legitimaban el campo del boxeo; empresarios, políticos, la prensa y boxeadores. Los acontecimientos deportivos de gran magnitud, como es el caso del match Firpo - Dempsey, sirven como un claro ejemplo de cómo gran parte de la prensa escrita, en este caso partimos del análisis de las fuentes primarias de los periódicos de La Prensa, La Nación, La Razón y Crítica "luchan" cada uno por imponer sus interpretaciones de la realidad, para la formación de cierta opinión pública, poniendo en circulación determinados discursos y sentidos y no otros. Formando y caracterizando cierto sentido de argentinidad, latinidad y masculinidad, cada una con sus respectivas otredades, produciendo una imagen y un sentido homogéneo de la argentina.

La Prensa y La Nación, durante la década del '20 eran los periódicos de mayor tirada y que marcaban un horizonte periodístico en Argentina, por lo tanto, conformaban en parte a la prensa hegemónica, representando y defendiendo los ideales del liberalismo económico y conservadurismo político. La Prensa y La Nación respondían a intereses políticos, sociales y económicos, que estaban más ligados a los intereses de las clases altas de la Argentina y a intereses de sectores de los Estados Unidos, luchaban por convertirse en "la voz de la clase dirigente y en la educadora de quienes ocupaban las altas esferas sociales" (Bontempo, 2012, p.66). Por lo tanto, no siguieron con tanta exaltación y criollismo las lógicas discursivas acerca de Luis Ángel Firpo como el ideal físico ${ }^{13}$, mental y moral de la argentina, como un ideal de masculinidad y como gran representante de la raza latina ${ }^{14}$, sino que lo hacían de una forma más neutral, sin ir en contra de las representaciones y discursos propios de los Estados Unidos. En cambio La Razón y Crítica eran periódicos comerciales, que representaba a la "voz del pueblo" (Bontempo, 2012, p.66). Más que nada Crítica se autodenomino, a partir de abril de 1923, como la "voz del pueblo", como el "diario popular", como "la voz autentica del pueblo argentino" y como el "representante de la voz popular" (Saítta, 1998). Por lo tanto, dentro de las lógicas discursivas que desplegaron estos dos periódicos, se desplegó, con un lenguaje coloquial e irónico, el sentimiento del criollismo y del sensacionismo, que procuraban demostrar y dejar sentado en la opinión pública de la argentina a la figura de Firpo como un ideal masculino popular argentino de la época. Digno representante de la raza latina, que iría a la capital mundial del boxeo a disputarles el título mundial de los pesos pesados, el cual era el título más importante de boxeo en ese momento. 
A pesar de las diferencias ideológicas y partidarias que tenían estos periódicos, alrededor de la pelea, antes, durante y después, y alrededor de la figura de Luis Ángel Firpo y de la de Jack Dempsey, construyeron determinados discursos acerca del cuerpo, la moral, la sexualidad y la nacionalidad argentina, en contra posición del cuerpo, la moral, la sexualidad y la nacionalidad estadounidense. Parte de la prensa escrita legitimó una determinada forma de ser argentino, ligada a lo criollo y lo latino y una determinada forma de ser estadounidense, ligada a lo yanqueé y lo sajón. Siempre bajo una lógica binaria, dentro de un proceso de alteridad constante, excluyente y negativo.

Los periódicos de La Razón y Crítica, produjeron y pusieron en circulación ciertas lógicas discursivas que enarbolaban exageradamente sentidos, saberes, imágenes, verdades y discursos de lo propio. Reafirmando ciertas características físicas, morales y mentales, principalmente atribuidas al sexo fuerte, dominante y perteneciente al mundo de lo público, por lo tanto al mundo deportivo (el masculino). Repudiando y despreciando los sentidos, saberes, imágenes, verdades y discursos que suponían, y por lo tanto le atribuían, ser propios de los norteamericanos. Tanto la figura de Firpo, como la de Dempsey, sirvieron como significantes vacíos, los cuales fueron llenados de sentido y significado por la prensa escrita argentina. De esta manera, formaron y delimitaron, los límites de la mismidad, por lo tanto de la argentinidad, lo criollo y la latinidad, reconociendo, tipificando y estereotipando al otro(s), a ese otro(s) estadounidense, yanqueé y sajón, representado en la figura de Jack Dempsey.

Esta disputa por imponer ciertos sentidos y significados a través de la pelea de boxeo, de la figura de Firpo, y de la figura de Dempsey, excedió el espacio del periodismo nacional. No solamente la prensa escrita argentina producía, transmitía y ponía en circulación determinados discursos y sentidos, sino que la prensa escrita internacional, y más precisamente la prensa escrita estadounidense, también lo hacía. Parte de la prensa escrita de Estados Unidos había hecho una campaña desprestigiando al ídolo argentino y sudamericano. Tildándolo de salvaje, inexperto, ignorante ${ }^{15}$, bruto, grande, torpe, lento, falto de técnica y ciencia boxística, todos estos supuestos atributos y características excedían a la figura de Firpo, ya que también se referían a características y atributos propios de los argentinos y latinos. Gran parte de la prensa escrita norteamericana no podía creer, ni entender, que un simple pugilista sudamericano se atreviera a ir a la capital mundial del boxeo, para demostrar que en América del Sur también había buen boxeo ${ }^{16}$, o por lo menos empezaba a haberlo. $Y$, por lo tanto, era posible disputarles el título mundial de pesos pesado.

Es probable que si no hubiera sido por la falta de tiempo para preparase para la pelea, la cantidad de peleas previas, los 4 fauls que no le cobraron a Dempsey y los segundos de más en los que él estuvo fuera del ring, Firpo hubiera ganado, y la historia sería completamente otra. El título mundial de los pesos pesados hubiera sido para la Argentina y para la raza latina, dejando totalmente "knockout" a la capital mundial del boxeo, y con esto, a toda la raza sajona. Hubiera significado la superioridad de la raza latina (inexperta, bruta y salvaje) sobre la raza sajona (técnica, eficiente e inteligente).

Parte de la prensa argentina, ante el "brutal" 17 ataque de los medios de comunicación estadounidenses, salió a defender a su ídolo nacional. El diario Crítica fue sin dudas, el defensor de la figura de Firpo, fue el defensor de su ídolo y el defensor del pueblo argentino. Poniéndose fuertemente en relación de conflicto con la prensa estadounidense. Por otro lado, ante esta "campaña ruin", los periódicos de La Prensa y La Nación no manifestaron una defensa hacia el 
ídolo del pueblo argentino, sino que siguieron en su postura neutral. Ya que ir en contra de los periódicos de Estados Unidos, significaría ir en contra de los ideales sociales, culturales, políticos y económicos que ellos mismos defendían.

\section{Firpo criollo y latino vs Dempsey yanqueé y sajón}

Un mes antes, pero más que nada, días previos a la pelea del siglo $X X, y$ días posteriores, los sentidos de lo masculino, lo nacional y criollo, lo latino y la "buena" moral, inundaban los periódicos, más que nada, de La Razón y de Crítica, con el objetivo de hacer ver y hacer creer que Luis Ángel Firpo era un ideal de cuerpo masculino popular argentino de la época. Proyectaron a Firpo como "una figura nacional; todo un símbolo en nuestro joven escenario deportivo; un ídolo de las multitudes" ${ }^{\prime 18}$, como un ideal de hombre masculino argentino, representante de la raza latina, valiente, fuerte, caballero, heterosexual, con todos las mujeres detrás de él, blanco, viril, atlético, noble, honesto, honrado, obstinado, bueno moralmente hablando, con gran corazón y espíritu templado. En contraposición, siguiendo la lógica planteada por el proceso de alteridad que ve al "otro como fuente de todo mal", se necesitaba de un otro, para poder justificar, y darle mayor sentido a estos discursos que estaban (re) produciendo la identidad nacional criolla, argentina y latina. Ese otro, ese no-nosotros, ese ellos, fue Jack Dempsey. Identificado como el representante de todos los hombres estadounidenses y el ejemplar de la raza sajona. Por lo tanto, los periódicos, en menor medida La Razón, y en mayor medida Crítica, fueron los que más produjeron y pusieron en circulación discursos, sentidos e imágenes representando a Jack Dempsey como un hombre ventajero, astuto ${ }^{19}$, cobarde, aprovechador, resistente, científico, metódico, calculador, como un hombre no caballero e inmoral.

El periódico de Crítica fue el que produjo y puso en circulación los discursos y sentidos más apasionantes y populares acerca de la pelea. Al igual que $\mathrm{La}$ Prensa, La Nación y La Razón, había mandado a un representante del diario a Nueva York, Manuel Hernández, para poder seguir lo más de cerca y fehacientemente posible el antes, durante y después del espectáculo deportivo, la opinión del público, los entrenamientos, la alimentación y las actividades por fuera de los entrenamientos que realizaban ambos boxeadores. Crítica fue el periódico que le dedico las más amplias notas, ubicadas en las primeras páginas, con espacios de "Firpo o Dempsey. Lo que opina la gente" 20 , los cuales eran secciones especiales donde aparecían los telegramas, mensajes y deseos de esperanza y victoria que la gente le mandaba a Firpo. Uno de los mensajes más conocidos que apareció en esta sección fue "Firpo, viejo, fájale a la criolla" ${ }^{21}$, realizado por los empleados del Banco Comercial del Azul. Estos mensajes también reflejaban los sentidos y sentimientos de admiración, exaltación, esperanza, patrióticos y criollos $^{22}$. Las caricaturas tampoco se quedaron atrás, las famosas "Firpisticas" ${ }^{23}$ y "¡Firpo, sí! ¡Dempsey, no!" ${ }^{4}$, hechas por el "Mono" Taborda, reforzaban constantemente los ideales y representaciones acerca de lo criollo (tomando mate amargo, comiendo mucha carne, carbonada, puchero, pan criollo, naranja, empanadas, escuchando tango, vestido como gaucho y tocando la guitarra) ${ }^{25}$, lo caballero, noble y honrado de Firpo, asociándolo muchas veces a Martin Fierro ${ }^{26}$. Mostrándolo, de esta manera, como un hombre ideal y autentico representante de la patria y de la raza. 
Por otro lado, a Dempsey lo representaban en las notas y más que nada en las caricaturas hechas por el "Mono" Taborda, como un boxeador que estaba siendo ayudado para ganar el título mundial de pesos pesados por empresarios, managers y el "Tío Sam" (Uncle Sam). El Tío Sam, gran símbolo de los Estados Unidos, siempre estaba representado con las orejas y nariz puntiaguda ${ }^{27}$, con cara "maléfica", con un bolso de dinero ${ }^{28}$ y siempre tratando de arrebatarle a Firpo el título mundial de los pesos pesados de una manera ilegal, aprovechándose de su supuesta honradez y caballerosidad. De esta manera, los espacios de "Firpo o Dempsey. Lo que opina la gente”, las “Firpisticas” y “¡Firpo, si!, ¡Dempsey, no!” representaban y asociaban lo yanqueé y estadounidense con lo ventajero, el cálculo, lo metódico, la frialdad, la racionalidad, el dinero, la astucia y la cobardía.

Todos estos discursos, imágenes y sentidos toman mayor sentido dentro de las primeras décadas del siglo XX, donde se instauraba poco a poco y reconocía que había un espíritu, una forma de ser sajón, que era propia de los Estados Unidos, la cual estaba orientada hacia un cultivo de la racionalidad tecno económica y su fascinación por el industrialismo, y por otro lado, había una forma y un espirito de ser latino, la que estaba caracterizada por los pueblos hispanoamericanos. Esta última estaba más orientada hacia el cultivo de la belleza, y no hacia una capacitación en la carrera mercantilista que amenazaba al mundo, por lo tanto era menos metódica y eficaz (Castro-Gómez, 2009). Ambos espíritus, en distintas esferas públicas, reflejaban su lucha por imponer su forma de ser como la forma de ser hegemónica y, por lo tanto, la que toda América tenía que adoptar y seguir. Una de esas esferas públicas fue la de los deportes. Por lo tanto, se puede ver claramente cómo la prensa escrita de la época, a partir de la pelea y de los boxeadores, puso en circulación ciertas lógicas discursivas que fomentaban, contribuían y respondían a la lucha de las dos grandes razas del continente americano. Ambas, en disputa por demostrar que su método de boxeo, sus hombres, y su raza, eran mejores que la otra, demostrando e imponiendo su poderío y hegemonía en todo el continente americano.

Principalmente, los periódicos de La Razón y, en menor medida, Crítica instalaron la idea de que dependiendo la raza que resultara victoriosa, iba a marcar el rumbo de los significados de valores y normas establecidos hasta el momento. En esta pelea chocaban dos temperamentos "el ardiente, insubordinado y tumultuoso de los americanos del Sur y el reflexivo, disciplinado y morigerado del americano del Norte, todo actividad productiva, todo calculo" ${ }^{29}$, chocan dos escuelas, por un lado la de Dempsey "que llamaríamos escuela clásica, que se ajusta a normas perfectamente estudiadas, reglamentadas y de eficacia comprobada por vieja experiencia" ${ }^{30}$ y "con esa serenidad espasmódica, calculadora y fría" ${ }^{31}$, y por el otro lado, la escuela de Firpo "que llamaríamos instintiva, que ataca tumultuosamente, con berrar la guardia y sin más preocupaciones que doblegar el obstáculo de un solo mazazo" ${ }^{2}$ y "con su ímpetu avasallador, peculiar en su raza y que lo caracteriza en todas sus peleas" ${ }^{\text {"3 }}$, su resultado podría "cambiar totalmente el significado de ciertos valores y modificar el concepto de normas hoy indiscutidas"34. "Latino el uno, sajón el otro. Latino puro, de padre italiano y de madre española, nacido, por lo demás, en país latino. Sajón el otro, y sajón puro" ${ }^{35}$. Este combate no era solo entre dos simples boxeadores, sino que estaban en combate las dos razas más importantes de América, la latina y la sajona.

La raza latina, situada en América del Sur y América Central, asociada con una forma de ser más instintivos, menos disciplinados, faltos de técnica, más pasionales y ardientes, arriesgados, rústicos ${ }^{36}$, e individualistas. Asociados más 
con la idea de un modelo precario, artesanal y pre industrial. Y la raza sajona, situada en América del Norte, con una forma de ser más meticulosa, metódica ${ }^{37}$, basada en el cálculo, la eficacia y la producción, asociándola con un modelo económico industrial. Dentro de esta forma de ser latino, del "espíritu latino" (Castro-Gómez, 2009, p.68), se encuentra lo criollo, los criollos son los hijos europeos, principalmente de los españoles, que nacieron en el continente americano de habla hispana. Firpo al ser hijo de madre española y padre italiano era completa y puramente criollo. A medida que fue pasando el tiempo fueron fundadores de la raza latina, por lo tanto, la categorización de "lo criollo" y "lo latino" puede asociarse a un mismo espíritu, a una misma forma de ser y representarse. Así como se puede asociar a las categorías de "lo latino" y "lo criollo", "lo yanqueé" también estaría vinculado con la misma lógica y espíritu de "lo sajón".

\section{Conclusiones}

Lo pelea arriba del ring duró poco, menos de cuatro minutos, pero las disputas sociales, económicas, culturales, raciales, sexuales y morales, que surgieron y giraron en torno a ella, y de alguna manera, la excedieron, duraron mucho más y fueron mucho más significativas. Los discursos y sentidos que fueron puestos en circulación, distribución, transmisión, producción y apropiación por parte de la prensa escrita argentina fueron los que le dieron forma y sentido a lo que hubiera sido una simple pelea de boxeo entre un estadounidense y un argentino. A partir de la famosa pelea del siglo XX, la prensa escrita, a pesar de sus diferencias políticas e ideológicas, visibilizó y se apropió del escenario para la conformación de los espacios de la mismidad y otredad. Produciendo y poniendo en circulación ciertos discursos y sentidos y no otros, en función de los intereses e ideales que cada una perseguía, con respecto masculinidad, nacionalidad, la moral, el cuerpo, la sexualidad y la raza.

Tanto Firpo, como Dempsey, sirvieron como significantes vacíos, en los cuales la prensa condenso múltiples sentidos. Esta pelea sirvió para demostrar y (re) afirmar quién era el estado-nación más fuerte económica, política y socialmente, quién pertenecía y por lo tanto representaba a la raza más viril, fuerte, resistente y caballera, quién era el medio de comunicación que tenía mayor poderío para lograr instalar sus propias interpretaciones de la realidad, y quién tenía mayor y mejor conocimiento de la técnica, el método y del mundo del boxeo. Sin duda, la prensa escrita tuvo un rol fundamental en la producción y puesta en circulación de cierta opinión publica en la población, legitimando y enarbolando sentidos nacionales, viriles, raciales y deportivos, dejando de lado y despreciando otros.

\section{Referencias}

Archetti, E. (2008). El potrero y el pibe: territorio y pertenencia en el imaginario del futbol argentino. Horizontes Antropológicos, Porto Alegre. 14(30), 259-282. http://dx.doi.org/10.1590/S0104-71832008000200013 
Auzzani, Á. (1953). El boxeo. Córdoba, Argentina: ED Ediciones Deportivas Ex. Conde.

Barrancos, D., Guy, D. y Valobra, A. (eds.). (2014). Moralidades y comportamiento sexuales. Argentina (1880-2011). Buenos Aires, Argentina: Biblos.

Bontempo, P. (2012). Editorial Atlántida. Un continente de publicaciones, 19181936. (Tesis de Doctorado). Universidad de San Andrés. Recuperado de: http://hdl.handle.net/10908/879.

Borrat, H (1989). El periódico, como actor del sistema político. Análisis, 12(1), 6780.

Castro-Gómez, S (2009). Latinos y sajones. Identidad nacional y periodismo en los años veinte. Nómadas. 30, 66-73. Recuperado de http://nomadas.ucentral.edu.co/index.php/component/content/article/19-pluralismoy-critica-en-las-ciencias-sociales-nomadas-30/224-latinos-y-sajones-identidadnacional-y-periodismo-en-los-anos-veinte

De Diego, J. L. (Dir.) (2006): Editores y políticas editoriales en Argentina, 18802000, Buenos Aires, Fondo de Cultura Económica.

Delgado, V. y Rogers, G. (Eds.) (2016): Tiempos de papel: Publicaciones periódicas argentinas (Siglos XIX-XX), La Plata, Editora Universidad Nacional de La Plata, Estudios/Investigaciones 60.

Delgado, V.; Mailhe, A. y Rogers, G. (Coord.) (2014): Tramas impresas. Publicaciones periódicas argentinas $(\mathrm{XIX}-\mathrm{XX})$, La Plata, Editora Universidad Nacional de La Plata, Estudios/Investigaciones 54.

Duschatzky, Silvia y Skliar, Carlos. (2000). La diversidad bajo sospecha. Reflexiones sobre los discursos de la diversidad y sus implicancias educativas. Cuaderno de Pedagogía. Rosario 4(7), 1-13.

Elías, N. y Dunning, E. (1992). Deporte y ocio en el proceso de la civilización. Madrid, España: Fondo de cultura económica.

Guerrero Arias, P. (2002). Antropología y Cultura. Una mirada crítica a la identidad, diversidad, alteridad y diferencia. Quito, Ecuador: Abya-Yala.

Guiamet, J. (2016). El trompeador Firpo: El boxeo dentro del imaginario del socialismo argentino en los años veinte. VIII Jornadas de Sociología de la UNLP, 3 al 5 de diciembre de 2014, Ensenada, Argentina. En Memoria Académica. Recuperado

http://www.memoria.fahce.unlp.edu.ar/trab eventos/ev.4735/ev.4735.pdf

Kircher, M. (2005). La prensa escrita: actor social y político, espacio de producción cultural y fuente de información histórica. Revista de Historia, (10), 115-122. Recuperado http://revele.uncoma.edu.ar/htdoc/revele/index.php/historia/article/view/219/210

Levinas, E. (2000). La huella del otro. México: Taurus.

Palla, J. (2018). Bitácora de Willie Farrell. Pugilismo, escenarios y negocios a ambos lados del Atlántico. (1920-1960). Claves. Revista de Historia, 4(7), 57-86. https://doi.org/10.25032//crh.v4i7.216

Qués, M. (2013). Medios y política. Imágenes, discursos y sentido. Buenos Aires, Argentina: Editorial Universitaria Rioplatense. 
Rocchi, F. (2016). A la vanguardia de la modernización: la incipiente formación de un campo publicitario en la Argentina durante la década de 1920. Estudios Interdisciplinarios de América Latina y el Caribe, 27(2), 47-76. Recuperado de http://eial.tau.ac.il/index.php/eial/article/view/1439

Saítta, S. (1998). Regueros de tinta: el diario "Crítica" en la década de 1920. Buenos Aires, Argentina: Sudamericana.

Sarlo, B. (1988). Una modernidad periférica: Buenos Aires, 1920 y 1930. Buenos Aires, Argentina: Ediciones Nueva Visión.

Scharagrodsky, P. (2019). ¿Cruzando fronteras? El primer cruce a nado del Río de la Plata, Uruguay-Argentina, 1923. Claves. Revista de Historia. 5(8) 211-233. https://doi.org/10.25032/crh.v5i8.9

Skliar, C. (2002). Alteridades y pedagogías. O... ¿y si el otro no estuviera ahí? Educação y Sociedade, 23(79), 85-123. https://doi.org/10.1590/S0101$\underline{73302002000300007}$

Zinni, H. (1976). Luis Ángel Firpo: era un buff?. Rosario, Argentina: Centro Editorial S.R.L.

\section{Fuentes Primarias}

Crítica. Buenos Aires, 1923.

La Nación. Buenos Aires, 1923.

La Prensa. Buenos Aires, 1923.

La Razón. Buenos Aires, 1923.

\section{Notas}

\footnotetext{
${ }^{1}$ Este trabajo reúne algunas ideas ya publicadas anteriormente en el 13 Congreso Argentino de Educación Física y Ciencias, 30 de septiembre al 4 de octubre de 2019, Ensenada, Argentina. Educación Física: Ciencia y profesión.

2 Este trabajo está enmarcado dentro del Proyectos de Investigación y Desarrollo UNLP "Prensa, Deporte y Educación Física. Discursos, prácticas y políticas. Argentina (1909-1936)", donde el Dr. Pablo Ariel Scharagrodsky cumple el rol de director.

${ }^{3}$ Hasta el momento el registro más antiguo, que nos proporciona Jonathan Palla, sobre un combate en la ciudad porteña corresponde al año 1829. El British Packet and Argentine News, periódico de la comunidad inglesa en Buenos Aires, publicó noticias sobre un match entre un inglés y un estadounidense, en un local cercano a Retiro. Ver British Packet, 24 de octubre de 1829 (Palla, 2008, p. 60).

${ }_{5}^{4}$ (La Vanguardia, 1922).

5 "Se evidencia que es un acto de salvajismo inaudito y repugnante, cuyo equivalente podría hallarse entre las tribus que viven en el centro de África, que viven fuera de todo contacto con la civilización, y aun así, dudamos de que la comparación resultaría favorable a los salvajes" ( $L a$ Vanguardia, 1922).

6 "La recaudación pasó de la suma de 1.250 .000 dólares -85.000 personas en el estadio y 25.000 fuera" (Crítica, 4 de octubre de 1923, p.1). "El encuentro fue presenciado por 85.000 personas y que los ingresos de boletería alcanzaron a la elevada suma de un millón doscientos cincuenta mil dólares" (La Nación, 15 de septiembre, p.1).
} 
7 "Es indescriptible la expectativa que ha despertado el gran match de mañana" (La Razón, 13 de septiembre de 1923, p.2).

8 "Toda América Latina está con Luis A. Firpo" (Crítica, 13 de septiembre de 1923, p.1).

${ }^{9}$ (Crítica, 1 de septiembre de 1923, p. 14).

10 "La Comisión de Boxeo de Nueva York se reunirá para considerar la descalificación del actual campeón mundial. La exhibición del 'film' cinematográfico pone en evidencia que Dempsey venció ilegalmente a Luis Firpo. Se asegura que el juez recién empezó a controlar el tiempo siete segundos después de que Dempsey cayera fuera del ring" (Crítica, 17 de septiembre de 1923, p. 1); "Afirmase la opinión de que el referee del match Firpo-Dempsey no fue imparcial" (La Razón, 17 de septiembre de 1923, p.8).

11 "Ídolo indiscutible de todo nuestro pueblo" (Crítica, 11 de septiembre de 1923, p.3).

12 "Se cree en el Perú que Firpo ha demostrado en Estados Unidos que la inferioridad de los pueblos de Sud América es tan solo un mito - (Hernández)". (Crítica, 4 de septiembre de 1923, p.); "Firpo (...) podía asegurar a sus oyentes que haría su mejor esfuerzo para conquistar el campeonato de peso-pesado, no solo para sí mismo, sino por su patria" (La Nación, 22 de agosto, p.2); "Miro tan alto que solo rio en el firmamento el azul y blanco de su bandera, y allá fue nuestro generosos sportsman como toda lealtad, con el mayor espíritu de sacrificio, a sostenerla en esta noble cruzada deportiva y a jugarse todo por ella" (La Nación, 9 de sept, p.9).

13 "Firpo ha sido una muestra sacada del inmenso stock, de hombres fuertes, valientes y corajudos, que posee la Argentina. Fue una muestra bien presentada y de óptima calidad que hace pensar en el grueso de la partida" (Crítica, 7 de septiembre de 1923, p.14).

14 "Homenaje de reconocimiento a quien ha prestigiado así, en la propia capital del deporte universal, el nombre argentino, y ha hablado al mundo en el lenguaje categórico del ring, de una raza de hombres fuertes, valientes y caballeresco" (Crítica, 15 de septiembre de 1923, p.1).

15 "Se lo acusa de ser un ignorante en el arte de boxear y se dice que posee un estilo ortodoxo, pero el hecho es que el sudamericano ha vencido en forma aplastante a dos de tanto prestigio como los nombrados" (Crítica, 2 de septiembre, p.6).

${ }^{16}$-"Este rudo pegador ha venido a ser algo así como el embajador espiritual, no de la Argentina solamente, sino de toda la raza de habla española en este medio hostil de ambiente sajón. Ha logrado a fuerza de puños, que los latinos seamos tenidos en cuenta y que no seamos únicamente temidos por el revólver y el cuchillo, sino también por los puños." (Crítica, 7 de septiembre de 1923, p.14).

17 "Con el motivo del match Firpo-Dempsey para el campeonato mundial, esta prensa norteamericana, grandiosa, inconmensurable, vocinglera que se titula independiente y exenta de vanos prejuicios ha comenzado una campaña ruin, indigna de ser publicada en este siglo de las libertades, por el mero hecho de ser Firpo un extranjero, un sudamericano procedente de Buenos Aires, capital del Brasil." (Crítica, 2 de septiembre de 1923, p.6); "Esta campaña me indigna y me hace renegar el patriotismo imbécil, aniquilador de todos los países. Ese patriotismo que anula los famosos tópicos de "América para la humanidad", "América, la tierra de todos." (Crítica, 2 de septiembre de 1923, p.6); "Hay en Nueva York una camarilla de policastros que se abroga la dirección de todos los asuntos de la famosa urbe. Esta camarilla, especie de -patota- de niños bien, al uso de otros países, es omnímoda, omnipotente. En uno de los últimos aquejaros, los chauvistas acordaron: -Rickard no es persona grata porque es de Texas-" (Crítica, 2 de septiembre de 1923, p.6).

${ }_{19}$ (Crítica, 11 de septiembre de 1923, p.3).

19 "Pero hay aun otro argumento. Dempsey es un hombre muy astuto. Es esta materia es el prototipo de su raza. No hay en el mundo un hombre más astuto que el norteamericano, quien asocia la frialdad del espíritu británico a la vivacidad y decisión del hombre nacido en el nuevo mundo" (Crítica, 9 de septiembre de 1923, p.6).

${ }_{20}$ (Crítica, 1 de septiembre de 1923, p.14).

21 "Un telegrama criollo" (Crítica, 11 de septiembre de 1923, p. 3).

22 "Firpo es un gran boxeador natural, a quien distingue las cualidades del peleador criollo, que muy conocidos son, por sentimientos patrióticos - Luis Costala" (Crítica, 4 de septiembre de 1923, p.10); "Sigue tan criollo como siempre" (Crítica, 7 de septiembre de 1923, p.14); "Acuérdate de Martin Fierro y acomódate a lo pampa - Empleados de la Aduana de Rosario" (Crítica, 13 de septiembre de 1923, p.13).

${ }_{23}$ (Crítica, 1 de septiembre de 1923, p. 3).

${ }_{24}^{24}$ (Crítica, 4 de septiembre de 1923, p. 7).

${ }^{25}$ (Crítica, 4 de septiembre de 1923, p.7); (Critica, 5 de septiembre de 1923, p. 7); (Crítica, 9 de septiembre de 1923, p. 4); (Crítica, 13 de septiembre, p.10).

${ }_{27}$ (Critica, 12 de septiembre de 1923, p. 2); (Crítica, 13 de septiembre de 1923, p. 10).

27 (Crítica, 12 de septiembre de 1923, p.2). 
${ }^{28}$ (Crítica, 15 de septiembre de 1923, p. 2).

${ }^{29}$ (La Razón, 14 de septiembre de 1923, p.4).

${ }^{30}$ (La Razón, 14 de septiembre de 1923, p.4).

31 (Crítica, 3 de septiembre de 1923, p.10).

32 (La Razón, 14 de septiembre de 1923, p.4).

33 (Crítica, 3 de septiembre de 1923, p.10).

34 (La Razón, 14 de septiembre de 1923, p.4).

${ }^{35}$ (La Razón, 13 de septiembre, p.6).

36 "Le debemos este entusiasmo colectivo por el box (...) porque, en efecto, rustico, iletrado, elemental, Firpo concentra hoy las esperanzas de todo el pueblo" (Critica, 15 de septiembre de 1923, p.1).

37 "Dempsey procede por método y es el mismo método que lleva en si como una manifestación de su raza" (Crítica, 6 de septiembre de 1923, p.2). 